\title{
Measuring Engineering Students' In-class Cognitive Engagement: Survey Development informed by Contemporary Educational Theories
}

\section{Mr. Benjamin David Lutz, Oregon State University}

Ben Lutz is a Postdoctoral Scholar in Engineering Education at Oregon State University. His research interests include innovative pedagogies in engineering design, conceptual change and development, schoolto-work transitions for new engineers, and efforts for inclusion and diversity within engineering. His current work explores how students describe their own learning in engineering design and how that learning supports transfer of learning from school into professional practice as well as exploring students' conceptions of diversity and its importance within engineering fields.

\section{Ms. Allyson Jo Ironside, Oregon State University}

Ally Ironside is a recent graduate from LeTourneau University where she studied Water Resources in Civil Engineering. She is currently fusing her technical background with her passion for education in pursuing a doctoral degree in Civil Engineering while conducting research in Engineering Education at Oregon State University. Her research interests include the adoption of teaching best practices in engineering and the personal epistemology development students.

\section{Dr. Nathaniel Hunsu, University of Georgia}

Nathaniel Hunsu is currently an assistant professor of engineering education at the University of Georgia. He is affiliated with the Engineering Education Transformational Institute and the school electrical and computer engineering at the university. He holds a Bachelor's degree in electronic and computer engineering from the Lagos State University in Nigeria, a Masters in Project management from the University of Sunderland, and a PhD in Educational Psychology from Washington State University. His research interests include learning and cognition, students' engagement, and the assessment of learning and students engagements, in engineering classrooms. His expertise also include the development and validation of measurement inventories, systematic reviews and meta-analysis, and quantitative research designs.

\section{Dr. Cassandra J. Groen, Virginia Tech}

Dr. Cassandra Groen is a post-doctoral researcher in the Department of Engineering Education and the Myers-Lawson School of Construction at Virginia Tech. Her primary research interests include professional identity formation in undergraduate civil engineering students, grounded theory methods, and theory development. Her current work includes the exploration of professional identity formation in civil engineering students who experience disabilities and the ways in which this identity is influenced by students' academic relationships, events, and experiences. Dr. Groen holds B.S. and M.S. degrees in Civil Engineering from the South Dakota School of Mines \& Technology.

\section{Dr. Shane A. Brown P.E., Oregon State University}

Shane Brown is an associate professor and Associate School Head in the School of Civil and Environmental Engineering at Oregon State University. His research interests include conceptual change and situated cognition. He received the NSF CAREER award in 2010 and is working on a study to characterize practicing engineers' understandings of core engineering concepts. He is a Senior Associate Editor for the Journal of Engineering Education.

\section{Dr. Olusola Adesope, Washington State University}

Dr. Olusola O. Adesope is an Associate Professor of Educational Psychology and a Boeing Distinguished Professor of STEM Education at Washington State University, Pullman. His research is at the intersection of educational psychology, learning sciences, and instructional design and technology. His recent research focuses on the cognitive and pedagogical underpinnings of learning with computer-based multimedia resources; knowledge representation through interactive concept maps; meta-analysis of empirical research, and investigation of instructional principles and assessments in STEM. 


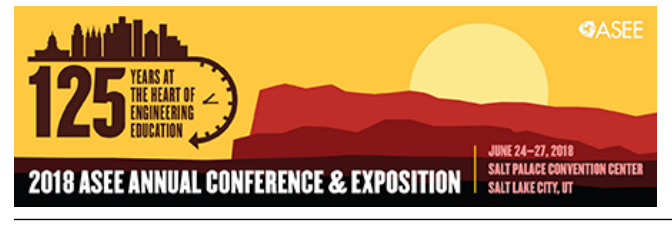

Paper ID \#22997

\section{Dr. Denise Rutledge Simmons P.E., Virginia Tech}

Denise R. Simmons, Ph.D., PE, LEED-AP, is an assistant professor in the Myers-Lawson School of Construction and in the Department of Civil \& Environmental Engineering, and an affiliate faculty of the Department of Engineering Education at Virginia Tech. She holds a B.S., M.S., and Ph.D. in civil engineering and a graduate certificate in engineering education - all from Clemson University. She has over 10 years of experience working for energy companies and as a project management consultant. Her research contributes to the advancement of labor and personnel issues in engineering broadly and specifically in the construction industry through two research areas: untangling the complex relationship between activities people become involved in - operationalized as engagement - and the technical and professional outcomes gained - operationalized as competencies. The broader impact of this work lies in achieving and sustaining productive, diverse and inclusive project organizations composed of engaged, competent people. Dr. Simmons' research is supported by awards from NSF, including a CAREER award. She oversees the Simmons Research Lab (www.denisersimmons.com), which is home to a dynamic, interdisciplinary mix of undergraduate and graduate students and a post-doctoral researcher from various colleges and departments at Virginia Tech who work together to explore engineering and construction human centered issues with an emphasis on understanding difference and disparity. 


\title{
Measuring Engineering Students' In-Class Cognitive Engagement: Survey Development Informed by Contemporary Educational Theories
}

\begin{abstract}
In this research paper, we examine the development of an instrument designed to measure students' in-class cognitive engagement. Cognitive engagement is a critical aspect of success in an engineering program; students who are more engaged are more likely to succeed. However, understanding how and in what ways engagement takes place remains a challenge. In this study, we describe the development of a survey informed by an existing theoretical framework that links overt, behavioral indicators to cognitive states of engagement. In this description, we present the results of an initial factor analysis, articulate the differences between anticipated factor structure and actual structure as a result of that analysis, and identify the improvements made from subsequent iterations of the survey. Results from the factor analyses suggest that inclass engagement should be defined and conceptualized as a combination of behavioral and cognitive scales, rather than either scale alone. However, further iterations are needed to arrive at a final composite measure of engagement at the student- and course-levels.
\end{abstract}

\section{Introduction}

Cognitive and social engagement is a critical component of an engineering students' educational experience. Students who are more engaged with their university, social groups, courses, and other aspects of university life are more likely to succeed and perform higher than their less engaged peers. As a result, it is critical that educators, administrators, and other key stakeholders, work to increase students' engagement within engineering classrooms and the field of engineering broadly. Though most engineering education researchers are in agreement regarding the importance of student engagement for learning and success in school, articulating how engagement is manifested in observable, measurable ways within the classroom remains a significant challenge within the community.

One particularly challenging aspect of measuring cognition is its imperceptibility. Cognition and engagement are primarily internal states that are typically self-reported. While some advanced technologies (e.g., fMRI, EEG) can infer cognitive engagement from detecting different kinds of synaptic or chemical activities within the brain, these approaches are of little practical use when measuring cognition or engagement in an authentic classroom context. In response to these practical limitations, Chi and Wylie (2014) have developed an ICAP framework that intentionally links overt, observable behaviors to cognitive modes of engagement. According to this framework, an observer (or self-reporting student) can identify particular behaviors associated with differing cognitive states of engagement. From these observable, behavioral indicators, researchers and educators can determine and enhance students' cognitive engagement in classroom activities.

To date, however, ICAP has been primarily used to advance discussions of theory with relatively less empirical work. As a result, our research team set out to develop a quantitative survey that would probe the degree to and frequency by which students performed certain behaviors, thus exhibiting varying degrees of cognitive engagement. In this paper, we describe the process of 
translating a theory of cognition into quantitative items for empirical use and practical classroom application. First, we describe the relevant background and literature that informed survey item development. Next, we provide an overview of the Spring 2017 distribution, statistical analyses, and measurement issues identified by the research team as a result of that distribution and analysis. Finally, we present the revised version of the instrument and explicate implemented changes as well as outline plans for the next round of survey distribution.

Because we describe the development and validation of a research instrument, and the not the results of an existing or valid instrument, the format for this particular paper differs slightly from that of a traditional research paper. Here, our methods are presented as the process of instrument development, while the results are the modifications made to the instrument as informed by development and our lessons learned. As a result, we do not intend to make claims regarding the "actual" engagement of student survey participants, rather our discussion focuses on the developmental process of the instrument itself.

\section{Background and Relevant Literature}

School engagement is a multifaceted construct that can be defined in terms of behavior, emotion, and cognition (Fredricks, Blumenfeld, \& Paris, 2004). Though behavioral and emotional engagement can be observed, the inability to directly observe cognitive engagement poses a significant empirical challenge. In the literature presented below, we first discuss the importance of cognitive engagement as a construct and the ways measurement can improve teaching and learning. Next, we present the ICAP framework which links cognitive engagement to overt, observable behaviors (Chi \& Wylie, 2014). This literature points toward the development of an instrument that can be used to measure student cognitive engagement and exhibits the usefulness of such an instrument to STEM educators.

\section{Cognitive Engagement}

Increasing student cognitive engagement remains a goal of engineering educators with numerous pedagogical strategies underscoring the importance of such engagement (Guthrie et al., 2004; Smith, Sheppard, Johnson, \& Johnson, 2005). For example, active learning has been linked to higher student performance in STEM classes (Freeman et al., 2014) in part due to relationship between student activity and cognitive engagement (Corno \& Mandinach, 1983). However, not all forms or modes of engagement are equally useful for learning. Students who are cognitively engaged may maintain varied levels of cognitive processing that can range from meaningful to shallow (Craik \& Lockhart, 1972). Meaningful cognitive processing allows for the connection, elaboration, and transfer of material while shallow processing remains disconnected, rote, and superficial (Christopher, Walker, Greene, \& Mansell, 2005). As aa result, many teaching and learning strategies aim to promote meaningful cognitive engagement of students, yet measuring whether or not these strategies meet this goal can prove challenging.

To measure cognitive engagement, studies have employed a variety metrics. Findings from a prominent study conducted by Meece et al. identified that goals were key influencers of and useful for determining individual cognitive engagement (Meece et al., 1988). This work laid the foundation for following studies that began to explore types strategies for measuring cognitive engagement. For example, Greene and Miller (1996) expanded upon Meece and colleagues' 
results by measuring meaningful and shallow cognitive engagement and its relationship to achievement (Greene \& Miller, 1996). In particular, they confirmed the relationship between perceived ability and student learning goals as linked to meaningful cognitive engagement (Greene \& Miller, 1996). This study emphasized the innate characteristics of engaged students and identified the need for further study exploring the impacts of classroom activities on students' cognitive engagement. Appleton et al. began this work through the development of their Student Engagement Instrument (SEI), which was developed based on a review of engagement-related literature and resulted in 30 items targeted at measuring general cognitive engagement (Appleton, Christenson, Kim, \& Reschly, 2006). While the SEI was initially developed for middle school and high school students, research has called for adaptations of this instrument to be applied to both postsecondary and course-level contexts (Appleton et al., 2006).

\section{ICAP Framework}

Despite its identified importance for learning, cognitive engagement is often a difficult construct to measure. Chi and Wylie developed the ICAP framework (Chi \& Wylie, 2014), which represents four modes of engagement: 1) Interactive, 2) Constructive, 3) Active, 4) Passive. The purpose of this framework is threefold. First, it brings further definition to generally-broad recommendations for actively engaging students (i.e., moving away from vague actions such as engage students). Second, it provides instructors with criteria to evaluate learning activities in relation to cognitive engagement. And third, it offers guidelines for the modification of existing assignments to promote active learning (Chi \& Wylie, 2014). In short, the ICAP framework utilizes the behaviors associated with and exhibited in active learning environments to observable, overt behaviors.

The four modes of the ICAP framework each comprise of a series of activities that are distinct to a particular mode. For example, interactive engagement, the highest mode of engagement of the ICAP framework, involves activities such as student discussions in which they explain their ideas to one another. To capture this activity within the framework, Chi and Wylie use verbs such as defending, asking, and debating to describe this mode of engagement. As a function of the hierarchical nature of the ICAP framework, a student who is identified as interactively engaged may also be constructively engaged. A constructively engaged student is positioned as one who generates new ideas and is described with verbs such as reflecting, integrating, and selfexplaining. Actively engaged students are similar to constructively engaged students; however, they differ in that actively engaged students manipulate content material without generating new ideas or concepts. Activities carried out by these students are often described by verbs such as repeat, rehearse, and copy. Lastly, passively engaged students are instruction-oriented and receive information through listening, reading and watching. Importantly, these modes of engagement are not rigid categories used to describe students. Individuals may demonstrate a range of engagement modes and behaviors throughout their learning, and may engage differently in different contexts and with different materials.

Several studies have used the ICAP framework to measure various forms of engagement. In one such study, Marzouk, Rakovic, and Winne (2016) employed the framework as a means to generate feedback for students to improve metacognitive skills. Similarly, Wang and colleagues 
utilized the ICAP framework to measure students' cognitive behavior within a massive open online course (MOOC) setting (Wang, Yang, Wen, Koedinger, \& Rosé, 2015). Data collected from the course included student discussion forums that were hand-coded in accordance with the ICAP framework to generate feedback on general student engagement within the MOOC environment-a context that maintains the potential to promote student anonymity and little engagement with peers. Though work to date is limited, the empirical associations between overt behaviors and cognitive engagement, as characterized by the ICAP framework, provide a useful starting point for designing a survey to probe for such behaviors.

\section{Methods}

The present work is part of a larger project that is designed to assess students' cognitive and social engagement both in and out of class (Ironside et al., 2017; Pitterson, Brown, Pascoe, \& Fisher, 2016). Here, we focus on the in-class, cognitive engagement section of the survey because the item generation and revision process can serve as a guide for subsequent iterations within and outside the present study. In this section, we provide an overview of item generation and present a factor analysis from the latest survey distribution during the Spring 2017 term. We then identify the issues revealed by the factor analysis results as situated within the ICAP framework and discuss discrepancies between our anticipated factors and the statistical results.

\section{Item Generation}

Using a combination of prior literature, faculty responses, and pilot testing, we created a list of survey items that referred to each of the four modes of cognitive engagement associated with the ICAP framework. Table 1 presents each generated item and their corresponding engagement category. Because cognitive engagement is invisible, items were generated primarily through extrapolation from the literature in which student behavior was conceptualized as enactments of cognitive engagement within a particular context (i.e., (Chi \& Wylie, 2014)). For example, Chi $\&$ Wylie note that when a student is actively engaged in a lecture, some behaviors they may potentially exhibit could be "copying solution steps" or "taking verbatim notes" (p. 221); therefore, we developed items that would probe corresponding student behaviors to varied levels of engagement. Each item was presented as a 5-point Likert-type scale question ranging from 1 (not at all descriptive of my in-class activity) to 5 (very descriptive of my in-class activity).

Table 1: Spring 2017 version of in-class cognitive engagement survey based on ICAP (Chi \& Wylie, 2014)

\begin{tabular}{|l|l|}
\hline Items & \multicolumn{1}{|c|}{ Item Description } \\
\hline \multicolumn{2}{|c|}{ Interactive } \\
\hline Q3 & I defend my approach to others when discussing course content. \\
\hline Q4 & I discuss my position with others regarding the course content. \\
\hline Q6 & I answer questions describing my perspective when discussing course content. \\
\hline Q5 & I ask questions to understand other students' perspectives when discussing course content. \\
\hline Q7 & I explain concepts to others when discussing course content. \\
\hline Q8 & I justify my perspective to others when discussing course content. \\
\hline Q10 & I evaluate alternatives with others when discussing course content. \\
\hline Q11 & I do not discuss course concepts with other students. \\
\hline
\end{tabular}




\begin{tabular}{|c|c|}
\hline Q9 & I work with other students to understand ideas or concepts regarding course content. \\
\hline \multicolumn{2}{|r|}{ Constructive } \\
\hline Q12 & I take notes in my own words. \\
\hline Q21 & I do not consider how course content relates to other courses. \\
\hline Q13 & I add my own notes to the notes provided by the teacher. \\
\hline Q14 & I draw pictures/diagrams/sketches to clarify course content. \\
\hline Q15 & My course notes include additional content to what the teacher provided. \\
\hline Q16 & I add my own content to the course notes during lecture. \\
\hline Q17 & I consider how multiple ideas or concepts relate. \\
\hline Q18 & I consider how lecture content relates to content from other courses. \\
\hline Q19 & I consider how lecture content relates to course assignments. \\
\hline Q20 & I compare and contrast lecture concepts to concepts from other courses. \\
\hline \multicolumn{2}{|r|}{ Active } \\
\hline Q22 & $\begin{array}{l}\text { I take verbatim notes (meaning word for word directly from the board/PowerPoint slide/doc } \\
\text { camera etc.). }\end{array}$ \\
\hline Q23 & $\begin{array}{l}\text { I copy solution steps verbatim (meaning word for word directly from the board/PowerPoint } \\
\text { slide/doc camera etc.). }\end{array}$ \\
\hline Q24 & I only copy the notes the teacher writes down. \\
\hline Q25 & I do not add my own notes to the course notes. \\
\hline Q26 & I apply current concepts being taught to previous course content. \\
\hline Q27 & I connect current concepts with previous course content. \\
\hline Q28 & I apply current solution steps with previous course content. \\
\hline Q29 & I connect current solution steps with previous course content. \\
\hline Q30 & I do not apply course content to previous content. \\
\hline \multicolumn{2}{|r|}{ Passive } \\
\hline Q31 & I listen to lectures without doing anything else. \\
\hline Q40 & I think about previous solution steps during the lecture. \\
\hline Q32 & I listen to what the teacher is saying and do not do anything else. \\
\hline Q33 & I do not think about course content during lecture. \\
\hline Q34 & I focus my attention on things other than course content during lecture. \\
\hline Q35 & I do not write notes during lecture. \\
\hline Q36 & I do not pay attention to course content during lecture. \\
\hline Q37 & I think about current concepts covered in this course. \\
\hline Q38 & I think about previous concepts covered in the course. \\
\hline Q39 & I think about solution steps during the lecture. \\
\hline
\end{tabular}

Given the alignment with the literature and prior work by Chi and Wylie (2014), we anticipated the factor structure for the initial version of the instrument to be the structure depicted in Figure 1. In particular, we expected a four-factor model in which the items generated for each dimension of engagement, posited by the ICAP framework, would constitute a single factor. We further describe the factor analysis and its implications for instrument development in the following sections. 


\section{Factor Analyses}

We conducted survey analysis in two phases. First, we conducted a preliminary confirmatory factor analysis (CFA) to test whether the items would load as proposed in our hypothesized model. Second, once items failed to load as anticipated, we conducted an Exploratory Factor Analysis (EFA) to examine the actual factor structure underlying the existing items using a subset $(n=240)$ of the data. EFA analysis was conducted using SPSS factor reduction while CFA analyses were conducted using SPSS AMOS ${ }^{\circledR}$.

\section{Phase 1: Confirmatory Factor Analysis}

Table 2 includes the reliability statistics for the proposed scales. The results of the CFA suggest that the items did not load as hypothesized. As such, fit-indices for the model were calculated as follows: confirmatory fix index $(\mathrm{CFI})=0.634$ and the root-mean-square error of approximation $($ RMSEA $)=0.1$. Models are desirable when CFI is greater than 0.95, and RMSEA is less than 0.06 (Rigdon, 1996). Therefore, a lack of fit was identified for this model.

Table 2: Reliability coefficients of anticipated four-factor model

\begin{tabular}{|l|l|l|}
\hline & Cronbach's Alpha & N of Items \\
\hline Interactive & 0.791 & 9 \\
\hline Constructive & 0.784 & 10 \\
\hline Active & 0.536 & 9 \\
\hline Passive & 0.458 & 10 \\
\hline
\end{tabular}

Phase 2: Exploratory Factor Analysis

Following the initial confirmatory factor analysis, we conducted an exploratory factor analysis $(n$ $=480$ ) to determine the actual loading pattern of the items within the instrument. Factors were extracted using Principal Axis Factoring and rotated using Oblimin rotation. Kaiser-Meyer-Olkin measure (KMO) was .932, suggesting the data was sufficient for EFA. The Bartlett's test of sphericity $\chi 2(55)=9195.89, p<0.001$ indicated that patterned relationships existed between items. Six factors were initially extracted from this analysis with only two items loading on the sixth factor. As a result, we specified a 5-factor extraction in a follow-up EFA. The factor loading of the outcomes is shown in Table 3, below. The five factors explained $46.3 \%$ of the cumulative variance in participants' responses. However, the five factors that emerged do not necessarily appear to align along any of the anticipated patterns identified through the ICAP framework. While one factor, Factor 3 shown in Table 3, appears to capture primarily active engagement, other active items are also distributed throughout other factors, suggesting some theoretical inconsistencies in the ways in which we operationalized the construct. 


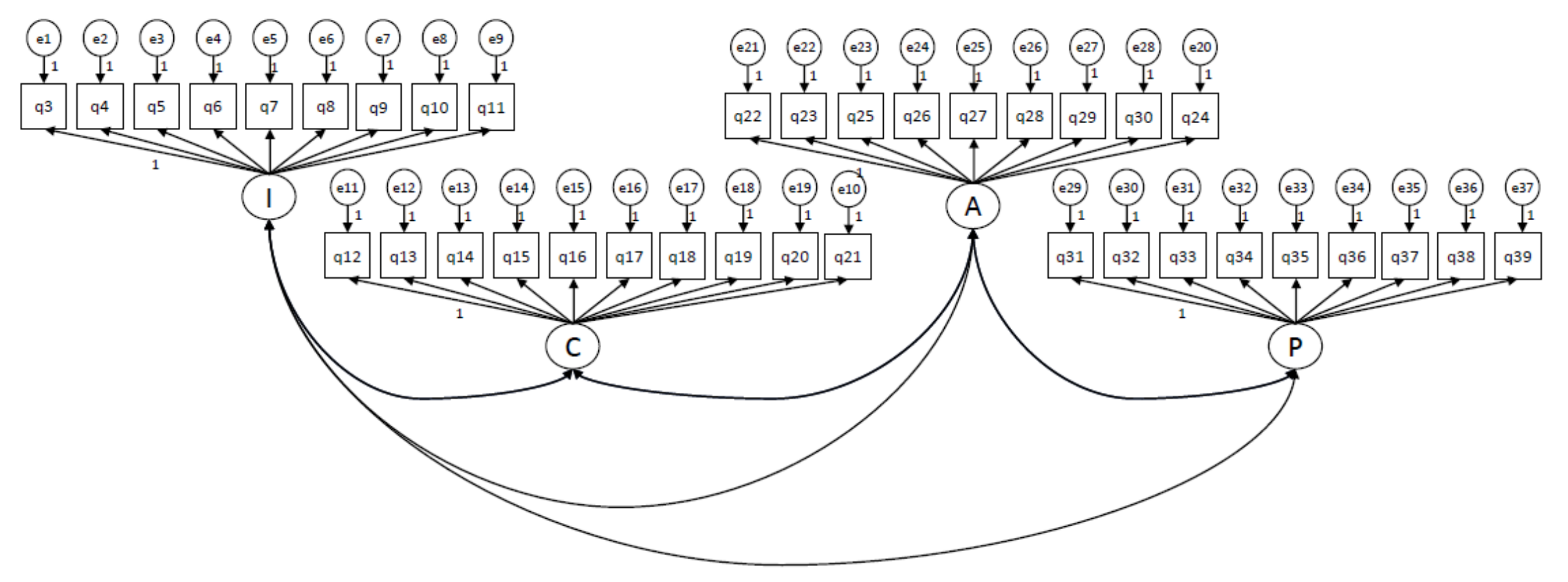

Figure 1: Hypothesized four-factor structure based on ICAP framework. 
Table 3: Factor loading derived from EFA analysis

\begin{tabular}{|c|c|c|c|c|c|c|c|}
\hline \multirow{2}{*}{$\begin{array}{c}\text { Item } \\
\text { Number }\end{array}$} & \multirow{2}{*}{$\begin{array}{c}\text { Item } \\
\text { Category* }\end{array}$} & \multirow{2}{*}{ Item Description } & \multicolumn{5}{|c|}{ Factors } \\
\hline & & & 1 & 2 & 3 & 4 & 5 \\
\hline Q29 & A8 & $\begin{array}{l}\text { I connect current solution steps with } \\
\text { previous course content. }\end{array}$ & 0.702 & & & & \\
\hline Q27 & A6 & $\begin{array}{l}\text { I connect current concepts with previous } \\
\text { course content. }\end{array}$ & 0.679 & & & & \\
\hline Q26 & A5 & $\begin{array}{l}\text { I apply current concepts being taught to } \\
\text { previous course content. }\end{array}$ & 0.651 & & & & \\
\hline Q38 & P8 & $\begin{array}{l}\text { I think about previous concepts covered } \\
\text { in the course. }\end{array}$ & 0.648 & & & & \\
\hline Q28 & A7 & $\begin{array}{l}\text { I apply current solution steps with } \\
\text { previous course content. }\end{array}$ & 0.589 & & & & \\
\hline Q39 & P9 & $\begin{array}{l}\text { I think about solution steps during the } \\
\text { lecture. }\end{array}$ & 0.579 & & & & \\
\hline Q40 & $\mathrm{P} 10$ & $\begin{array}{l}\text { I think about previous solution steps } \\
\text { during the lecture. }\end{array}$ & 0.573 & & & & \\
\hline Q18 & $\mathrm{C} 7$ & $\begin{array}{l}\text { I consider how lecture content relates to } \\
\text { content from other courses. }\end{array}$ & 0.569 & & & & \\
\hline Q17 & C6 & $\begin{array}{l}\text { I consider how multiple ideas or concepts } \\
\text { relate. }\end{array}$ & 0.547 & & & & \\
\hline Q37 & $\mathrm{P} 7$ & $\begin{array}{l}\text { I think about current concepts covered in } \\
\text { this course. }\end{array}$ & 0.538 & & & & \\
\hline Q19 & $\mathrm{C} 8$ & $\begin{array}{l}\text { I consider how lecture content relates to } \\
\text { course assignments. }\end{array}$ & 0.51 & & & & \\
\hline Q20 & C9 & $\begin{array}{l}\text { I compare and contrast lecture concepts } \\
\text { to concepts from other courses. }\end{array}$ & 0.441 & & & & \\
\hline Q31 & $\mathrm{P} 1$ & $\begin{array}{l}\text { I listen to lectures without doing anything } \\
\text { else. }\end{array}$ & 0.404 & & & & \\
\hline Q32 & $\mathrm{P} 2$ & $\begin{array}{l}\text { I listen to what the teacher is saying and } \\
\text { do not do anything else. }\end{array}$ & & & & & \\
\hline Q36 & P6 & $\begin{array}{l}\text { I do not pay attention to course content } \\
\text { during lecture. }\end{array}$ & & 0.809 & & & \\
\hline Q33 & P3 & $\begin{array}{l}\text { I do not think about course content } \\
\text { during lecture. }\end{array}$ & & 0.709 & & & \\
\hline Q34 & $\mathrm{P} 4$ & $\begin{array}{l}\text { I focus my attention on things other than } \\
\text { course content during lecture. }\end{array}$ & & 0.623 & & & \\
\hline Q35 & P5 & I do not write notes during lecture. & & 0.579 & & & \\
\hline Q21 & $\mathrm{C} 10$ & $\begin{array}{l}\text { I do not consider how course content } \\
\text { relates to other courses. }\end{array}$ & & 0.548 & & & \\
\hline Q11 & I8 & $\begin{array}{l}\text { I do not discuss course concepts with } \\
\text { other students. }\end{array}$ & & 0.546 & & -0.475 & \\
\hline Q30 & A9 & $\begin{array}{l}\text { I do not apply course content to previous } \\
\text { content. }\end{array}$ & & 0.497 & & & \\
\hline Q22 & A1 & $\begin{array}{l}\text { I take verbatim notes (meaning word for } \\
\text { word directly from the board/PowerPoint } \\
\text { slide/doc camera etc.). }\end{array}$ & & & 0.789 & & \\
\hline
\end{tabular}




\begin{tabular}{|c|c|c|c|c|c|c|}
\hline Q23 & $\mathrm{A} 2$ & $\begin{array}{l}\text { I copy solution steps verbatim (meaning } \\
\text { word for word directly from the } \\
\text { board/PowerPoint slide/doc camera etc.). }\end{array}$ & & 0.76 & & \\
\hline Q24 & A3 & $\begin{array}{l}\text { I only copy the notes the teacher writes } \\
\text { down. }\end{array}$ & & 0.571 & & \\
\hline Q4 & $\mathrm{I} 2$ & $\begin{array}{l}\text { I discuss my position with others } \\
\text { regarding the course content. }\end{array}$ & & & 0.715 & \\
\hline Q9 & I9 & $\begin{array}{l}\text { I work with other students to understand } \\
\text { ideas or concepts regarding course } \\
\text { content. }\end{array}$ & & & 0.666 & \\
\hline Q3 & I1 & $\begin{array}{l}\text { I defend my approach to others when } \\
\text { discussing course content. }\end{array}$ & & & 0.663 & \\
\hline Q8 & I6 & $\begin{array}{l}\text { I justify my perspective to others when } \\
\text { discussing course content. }\end{array}$ & & & 0.662 & \\
\hline Q7 & I5 & $\begin{array}{l}\text { I explain concepts to others when } \\
\text { discussing course content. }\end{array}$ & & & 0.644 & \\
\hline Q10 & I7 & $\begin{array}{l}\text { I evaluate alternatives with others when } \\
\text { discussing course content. }\end{array}$ & & & 0.566 & \\
\hline Q6 & I4 & $\begin{array}{l}\text { I answer questions describing my } \\
\text { perspective when discussing course } \\
\text { content. }\end{array}$ & & & 0.529 & \\
\hline Q5 & $\mathrm{I} 3$ & $\begin{array}{l}\text { I ask questions to understand other } \\
\text { students' perspectives when discussing } \\
\text { course content. }\end{array}$ & & & 0.495 & \\
\hline Q13 & $\mathrm{C} 2$ & $\begin{array}{l}\text { I add my own notes to the notes provided } \\
\text { by the teacher. }\end{array}$ & & & & 0.827 \\
\hline Q16 & $\mathrm{C} 5$ & $\begin{array}{l}\text { I add my own content to the course notes } \\
\text { during lecture. }\end{array}$ & & & & 0.736 \\
\hline Q15 & $\mathrm{C} 4$ & $\begin{array}{l}\text { My course notes include additional } \\
\text { content to what the teacher provided. }\end{array}$ & & & & 0.674 \\
\hline Q12 & $\mathrm{C} 1$ & I take notes in my own words. & & & & 0.517 \\
\hline Q25 & A4 & $\begin{array}{l}\text { I do not add my own notes to the course } \\
\text { notes. }\end{array}$ & 0.447 & & & -0.504 \\
\hline Q14 & C3 & $\begin{array}{l}\text { I draw pictures/diagrams/sketches to } \\
\text { clarify course content. }\end{array}$ & & & & \\
\hline
\end{tabular}

*The "Item Category" represents the cognitive engagement mode that the item was initially intended to measure. For example, "A 8 " indicates the $8^{\text {th }}$ item developed to measure Active engagement, "P10" is the $10^{\text {th }}$ item intended to measure Passive engagement, and so on.

\section{Issues with Current Instrument}

As shown in Table 3, the items do not load as anticipated from the ICAP theoretical model. Here, we posit a few potential reasons for this loading and offer some suggestions for mitigating these issues in the next iteration of instrument development. In particular, we will discuss issues with discerning behavior, cognition, and borderline cases as well as revisit assumptions made regarding classroom behavior broadly.

\section{Conceptual Overlap}

One important aspect of the ICAP framework is the ability to assess cognitive states from observable, overt behaviors. However, in practice - at least in this data set - distinguishing 
between different modes may be more challenging than theorized. A closer examination of Factor 2 in Table 3 suggests that students are responding to items in this factor from the perspective of things that they don't do rather than passive engagement (e.g., I do not pay attention, I do not take notes). While the items were designed with some reverse scored-items within each ICAP mode, the negative items loaded together, irrespective of engagement category. Further, upon examining Factor 5 in Table 3, the behaviors indicated by students appear to coalesce around activities related to note-taking as an overarching activity. This is in contrast from our initial conceptions of these items in which we sought to discern active note taking (i.e., notes are copied verbatim) from constructive note taking (i.e., knowledge is built-on or added to the verbatim notes). While a researcher may theoretically observe the behaviors that distinguish passive notetaking (i.e., a student copying an instructor's notes) from active notetaking (i.e., a student is adding to an instructor's notes), these activities may occur in closeenough proximity that students do not interpret them as two distinct activities. In other words, students may interpret and respond to all questions about notetaking in the same way regardless of notetaking strategy.

\section{Potential for Disengagement}

One assumption that seems to support the ICAP framework within the initial survey was the belief that when students are in the classroom, they are engaged. This makes sense, as it is not necessarily useful to discuss the theoretical links between learning and disengagement; however, in practice, it cannot be assumed that students are always engaged as outlined in the ICAP dimensions. For example, in Factor 2 in Table 3, the intent of the passive items was to distinguish behavioral characteristics from those that make them active. Item P5 (i.e., I do not write notes during lecture) and others were designed to assess the degree to which students were listening and simultaneously following along during lecture versus solely copying notes. In practice, however, the factor structure regarding negatively worded items seems to have measured the amount of time students spent doing activities generally unrelated to the course. Indeed, our results suggest the need to explore the frequency or degree to which students are not present or cognitively engaged with the material during the class (e.g., doing homework for another class, sleeping, playing videogames in the back row, etc.).

\section{Results}

In order to address the issues that arose during the spring 2017 survey implementation, we conducted another iteration of revision and refinement guided in part by two other related projects. The content is beyond the scope of this work-in-progress paper, but research with both faculty (Ironside et al., 2017) and students (Ironside, Lutz, \& Brown, 2018, forthcoming) informed this round of revisions in addition to the statistical tests previously described. Soliciting additional perspectives helped give the research team a better understanding of the meaning associated with different items and allowed us to modify items to enhance the usefulness of the instrument for our intended stakeholders (i.e., engineering faculty). The following sections discuss the ways we addressed the two issues noted above and provide an overview of the revised instrument

Table 4 presents the revised instrument that was administered in the Fall 2017 term. 
Table 4: Updated survey for Fall 2017 distribution.

\begin{tabular}{|c|c|}
\hline \multirow{4}{*}{ Interactive } & I defend my approach to others when discussing course content. \\
\hline & I discuss my position with others regarding the course content. \\
\hline & I explain concepts to others when discussing course content. \\
\hline & I justify my perspective to others when discussing course content. \\
\hline \multirow{4}{*}{$\begin{array}{l}\text { Constructive } \\
\text { (Cognitive) }\end{array}$} & I ask myself questions to make sure I understand the course content \\
\hline & $\begin{array}{l}\text { I try to think through a topic and decide what I am supposed to learn from it } \\
\text { rather than just reading it over }\end{array}$ \\
\hline & I try to determine which concepts I don't understand well in this course. \\
\hline & I set goals for myself in order to direct my activities. \\
\hline \multirow{3}{*}{$\begin{array}{l}\text { Constructive } \\
\text { (Behavioral) }\end{array}$} & I add my own notes to the notes provided by the teacher. \\
\hline & My course notes include additional content to what the teacher provided. \\
\hline & I add my own content to the course notes. \\
\hline \multirow{4}{*}{ Active (Cognitive) } & I connect current concepts with previous course content. \\
\hline & I apply current solution steps with previous course content. \\
\hline & I think about previous concepts covered in the course. \\
\hline & I consider how multiple ideas or concepts relate. \\
\hline \multirow{3}{*}{ Active (Behavioral) } & $\begin{array}{l}\text { I take verbatim notes (meaning word for word directly from the } \\
\text { board/PowerPoint slide/doc camera etc.). }\end{array}$ \\
\hline & $\begin{array}{l}\text { I copy solution steps verbatim (meaning word for word directly from the } \\
\text { board/PowerPoint slide/doc camera etc.). }\end{array}$ \\
\hline & I only copy the notes the teacher writes down. \\
\hline \multirow{4}{*}{ Passive } & I pay attention to my teacher or whomever is speaking. \\
\hline & $\begin{array}{l}\text { I follow along with my teacher or whomever is speaking when they discuss } \\
\text { examples. }\end{array}$ \\
\hline & I listen when my teacher or whomever is speaking. \\
\hline & I follow along with the activities that take place during the course. \\
\hline \multirow{3}{*}{ Disengagement } & I do not think about course content. \\
\hline & I do not pay attention to course content. \\
\hline & I focus my attention on things other than course content. \\
\hline
\end{tabular}

\section{Addition of the Disengagement Scale}

The exploratory factor analysis suggested the potential need for a "disengagement" scale. That is, while the ICAP framework rightfully assumes that students are engaged at some level, we wanted to introduce the possibility for students to discuss times when they might not be engaged in any behaviors associated with in-class cognitive engagement. Therefore, we developed the tentatively-named disengagement scale to gain a better understanding of the degree to or the frequency with which students enact behaviors that are unrelated to or indicate no engagement with in-class lectures, discussions, or activities. Focusing on the negatively-worded items from the earlier iteration, we revised the list to probe for behaviors that indicated a lack of attention or engagement (e.g., I do not pay attention to course content). 


\section{Articulating Conceptual Overlap}

In theory, the differences between the various modes of ICAP engagement are clear; but in practice, those boundaries are more transient and inconsistent. While it is possible for a trained observer to distinguish between different modes of engagement, the differences for most participants are too small to be meaningfully discerned. Therefore, we developed complementary questions that ask about self-reported cognitive states in addition to behaviors. These items were integrated from a well-known, existing instrument subscale, the Motivated Strategies for Learning Questionnaire (MSLQ) (Pintrich, Smith, Garcia, \& McKeachie, 1993), and were added to triangulate evidence for and more accurately differentiate among various modes of engagement. Specifically, we leveraged items from the self-regulation subscale of the MSLQ to corroborate constructive cognitive engagement. In this way, we probe both cognitive states and behavioral self-reports to more accurately focus on and distinguish between different levels of engagement.

\section{Conclusions and Future Development}

Student engagement in classroom learning activities is critical for success and developing a deep conceptual understanding of engineering content. However, measuring such engagement remains a challenge for the engineering and education communities. The ICAP framework offers a promising avenue for instrument development in this area because it links observable, overt behaviors to unobservable cognitive states. Therefore, engagement can be inferred from the kinds of behaviors students exhibit as they work and interact within a formal classroom context. However, while the types of cognitive engagement are clearly bounded theoretically, the empirical differences as observed in practice are less defined. As a result, our latest instrument iteration combines both measures of behavior and cognition to triangulate responses and add resolution to the measurement of student engagement.

The larger project of survey development is entering its second year, and the section concerning students' in-class, cognitive engagement is in its final stages. In Fall 2017, the survey was distributed to 618 students across courses of varying size, undergraduate academic level, and content focus in engineering. Another round of factor analyses will be conducted with our new round of survey data, and items will be revised, reworded, and removed as necessary.

\section{References}

Appleton, J. J., Christenson, S. L., Kim, D., \& Reschly, A. L. (2006). Measuring cognitive and psychological engagement: Validation of the Student Engagement Instrument. Journal of School Psychology, 44(5), 427-445.

Chi, M. T., \& Wylie, R. (2014). The ICAP framework: Linking cognitive engagement to active learning outcomes. Educational psychologist, 49(4), 219-243.

Corno, L., \& Mandinach, E. B. (1983). The role of cognitive engagement in classroom learning and motivation. Educational psychologist, 18(2), 88-108.

Craik, F. I., \& Lockhart, R. S. (1972). Levels of processing: A framework for memory research. Journal of verbal learning and verbal behavior, 11(6), 671-684.

Fredricks, J. A., Blumenfeld, P. C., \& Paris, A. H. (2004). School engagement: Potential of the concept, state of the evidence. Review of Educational Research, 74(1), 59-109. 
Freeman, S., Eddy, S. L., McDonough, M., Smith, M. K., Okoroafor, N., Jordt, H., \& Wenderoth, M. P. (2014). Active learning increases student performance in science, engineering, and mathematics. Proceedings of the National Academy of Sciences, 111(23), 8410-8415.

Greene, B. A., \& Miller, R. B. (1996). Influences on achievement: Goals, perceived ability, and cognitive engagement. Contemporary Educational Psychology, 21(2), 181-192.

Guthrie, J. T., Wigfield, A., Barbosa, P., Perencevich, K. C., Taboada, A., Davis, M. H., ... Tonks, S. (2004). Increasing reading comprehension and engagement through conceptoriented reading instruction. Journal of educational psychology, 96(3), 403.

Ironside, A., Lutz, B., \& Brown, S. (2018, forthcoming). Student Perspectives on Cognitive Engagement: Preliminary Analysis from the Course Social and Cognitive Engagement Surveys. Paper presented at the American Society for Engineering Education Annual Conference, Salt Lake City, UT.

Ironside, A., Pitterson, N., Brown, S., Quardokus Fisher, K., Gestson, S., Simmons, D., \& Adesope, O. (2017). Incorporating Faculty Sense Making in the Implementation and Modification of an Instrument to Measure Social and Cognitive Engagement. Paper presented at the American Society for Engineering Education Annual Conference, Columbus, $\mathrm{OH}$.

Marzouk, Z., Rakovic, M., \& Winne, P. H. (2016). Generating Learning Analytics to Improve Learners' Metacognitive Skills Using nStudy Trace Data and the ICAP Framework. Paper presented at the LAL@ LAK.

Meece, J. L., Blumenfeld, P. C., \& Hoyle, R. H. (1988). Students' goal orientations and cognitive engagement in classroom activities. Journal of educational psychology, 80(4), 514.

Pintrich, P. R., Smith, D. A., Garcia, T., \& McKeachie, W. J. (1993). Reliability and predictive validity of the Motivated Strategies for Learning Questionnaire (MSLQ). Educational and psychological measurement, 53(3), 801-813.

Pitterson, N. P., Brown, S., Pascoe, J., \& Fisher, K. Q. (2016). Measuring cognitive engagement through interactive, constructive, active and passive learning activities. Paper presented at the Frontiers in Education Conference (FIE), 2016 IEEE.

Smith, K. A., Sheppard, S., Johnson, D. W., \& Johnson, R. T. (2005). Pedagogies of engagement: Classroom-based practices. Journal of Engineering Education, 94(1), 87101.

Walker, C. O., Greene, B. A., \& Mansell, R. A. (2006). Identification with academics, intrinsic/extrinsic motivation, and self-efficacy as predictors of cognitive engagement. Learning and individual differences, 16(1), 1-12.

Wang, X., Yang, D., Wen, M., Koedinger, K., \& Rosé, C. P. (2015). Investigating How Student's Cognitive Behavior in MOOC Discussion Forums Affect Learning Gains. International Educational Data Mining Society.

Weinstein, C. (1986). The teaching of learning strategies. Handbook of research on teaching, 315-327. 